Article

\title{
Spatial Distribution of Population Density and Pressure on Sustainable Cropland Use in Shandong Province in China during the 17th-20th Century
}

\author{
Yu Ye ${ }^{1,2, *}$, Xueqiong Wei ${ }^{1}$, Xiuqi Fang ${ }^{1}$, Yikai Li $^{1}$ \\ ${ }^{1}$ School of Geography, Faculty of Geographical Science, Beijing Normal University, Beijing 100875, China; \\ ${ }^{2}$ Key Laboratory of Environment Change and Natural Disaster, Ministry of Education, BNU, Beijing 100875, \\ China \\ * Correspondence: yeyuleaffish@bnu.edu.cn; Tel.: +86--132-418-4630
}

\begin{abstract}
Cropland area per capita and pressure index on cropland is the important parameters measuring the social vulnerability and sustainability in the perspective of food security in a certain region in China during the historical periods. This study reconstructs the spatial distribution change of cropland area per labor/household and pressure index on cropland during the 17th-20th century by the methods of historical documents, regression analysis, pressure index model and GIS. Then it analyzed the impacting process of climate change and sustainability of cropland use during the different periods. It draws conclusions: (i) the spatial difference of labor/household density was obvious which had the same pattern as cropland distribution during the same periods, which is higher density in three agricultural areas. (ii) Cropland area per capita was relatively higher during the 17th-18th century, which were above 0.4 ha/person in majority counties and distributed homogenously. Till the 19th century and the beginning of 20th century, cropland area per capita in large amount of regions decreased below $0.2 \mathrm{ha} /$ person embodying the increase of social vulnerability and unsustainability at that time. (iii) Pressure index on cropland also showed the similar spatial pattern as cropland area per capita which presented lower threshold than nowadays. During the 17th-18th century there was no pressure on cropland. While, in the 19th century and at the beginning of 20th century, two high value centers of pressure index on cropland appeared in Middle Shandong and the Jiaodong region, pressure on sustainable cropland use increased obviously and a food crisis is probably created. (iv) Higher sustainable extent of cropland use corresponds to cold period, and lower sustainable extent of cropland use corresponds to warm period in Shandong over the past 300 years. The turning point of 1680s from dry to wet attributes to the decrease of sustainable extent of cropland use in Shandong not very distinctively. More and more pressure on sustainability of cropland use finally since the beginning of 20th century would intensify the social conflict and increase the probability of social revolts.
\end{abstract}

Keywords: Pressure on cropland; Labor / household density; Shandong Province in China; The 17th20th century

\section{Introduction}

Human interference with the climate system is occurring, and climate change is posing risks for natural systems and human sustainable development. The core concept of the fifth assessment report of Work Group II of Intergovernmental Panel on Climate Change (IPCC WGII AR5) is the theme of impact, adaptation and vulnerability related to climate change. It illustrated that risk of climaterelated results from the interaction of climate-related hazards (including hazardous events and trends) with the vulnerability and exposure of human and natural systems (James et al., 2001; Field et al., 2014). In the historical traditional agricultural society of China, climate change directly impacts the level of food production as starting point, and finally hinders the human living improvement and social development by a forcing-responding chain of climate change-agriculture (pasture) harvestfood supply amount per capita - famine-social stability (Fang et al., 2014). Under certain hazards and 
physical exposure, human society's ultimate affected extent and sustainability development depends on the social vulnerability and human adaptation actions.

In majority studies on the impact of historical climate change and adaptation nowadays, climate change and society stability results have been well expressed. For example, some typical researchers analyzed the impact of climate change on violent conflict in Europe over the last millennium (Richard and Wagner, 2010), the relationship between climate and the collapse of Maya civilization (Haug et al., 2003), North Atlantic seasonality and implications for Norse colonies (Patterson et al., 2010), the relationship between sun, climate, hunger and mass migration (Hsu, 1998), linkage of climate with Chinese dynastic change (Zhang et al., 2010) and so on. However, some intermediate links such as population, agricultural production, policy adjustment and so on in the impacting process and society vulnerability have been less characterized.

In China, there have been some researchers discussing the Chinese population and cropland area mainly from the perspective of historical or agricultural geography. For example, Ge (2002) studied the history of Chinese demographic composition, population change and distribution; $\mathrm{Li}$ (1999) analyzed the impact of climate change on several times of Chinese historical population fluctuation; He (1988) firstly evaluated the ancient land data in China; other researchers (Bian, 1995; Wan, 2000; Shi, 2000; Geng, 2000; Zhou, 2001) evaluated Chinese historical land data over the years and much of their work has produced methods for data correction and estimation of Chinese population and cropland area. Recently, scientists working in the field of global change have reconstructed the spatial distribution of historical cropland cover in China (Ge, 2003; He et al., 2011), or regions in China (Xie et al., 2013; Tian et al., 2012; Ye and Fang, 2012; Ye and Fang, 2009). However, above researches on agricultural production had not been well combined with impacts of historical climate change to explore the dynamic of climate-related risks. Pressure index on cropland was firstly put forward by Cai et al. (2002) and extensively used for evaluating food security in a certain region nowadays (Ren et al., 2008; Liu and Cai, 2010). Those indexes such as population density, cropland area per capita, pressure index on cropland, and so on are important parameters which can represent the society vulnerability in perspective of food security, and is relatively easy to obtain and can be used in the research on the impact of historical climate change and social sustainability development.

North China locates in the northern temperate monsoon belt, and variability of temperature and precipitation is significant. It has both higher sensitivity and certain adaptation ability to the impact of climate change. In addition, it is the administrative center of traditional agricultural area in China during the Qing Dynasty. Impact and response process of climate change in this region can directly relate to the social stability, which is often preferentially considered by central government. There have been many researches on the impact of climatic disasters and its response in this region. These researches include response and adaptation to climate change indicated by the relationship between revolt and drought-flood in Shandong Province during middle and late Qing Dynasty (Ye, et al., 2004), a case study on impact of extreme climate events in the early Qing Dynasty (Fang et al., 2007), migration and reclamation in Northeast China in response to climatic disasters in North China over the past 300 years (Ye and Fang, 2013), revolts frequency in North China Plain during 1644-1911 and its relationship with climate (Xiao, 2011), social responses in Eastern Inner Mongolia to flood/drought-induced refugees from the North China Plain during 1644-1911 (Xiao et al., 2013) and so on. They focus on the impact and response process of historical climate change and are mostly base on the method of comparison of time series, less attention is paid on social vulnerability and few spatial distribution results are represented.

This article firstly reconstructs the spatial distribution change of the labor/household density, cropland area per capita and pressure index on cropland in Shandong Province during the 17th-20th century. It will be used to estimate change of social vulnerability and sustainability in perspective of food security in this region during the historical periods and provide fundamental data for research on historical climate change impact and adaptation. 


\section{Research area}

This paper takes modern Shandong province in China as research area. It locates in mid-latitude area of north hemisphere, within the range of N34cropland in Shandong Province during theslands reach to38 $23^{\prime} \mathrm{N}$ ), including 110 cities or counties. In the Qing dynasty, Shandong province had 10 districts (named as Fu), 3 states directly under executive secretariat (named as Zhili states), 8 scattered states under Fu (named as San states) and 96 counties (Niu, 1990). The administrative boundaries of some counties in Shandong province had changed, however, it mainly attributed to the split and combine of counties. So, convenient for comparing with modern results, according to administrative changes we converted historical data into the following indexes based on modern boundaries of counties.
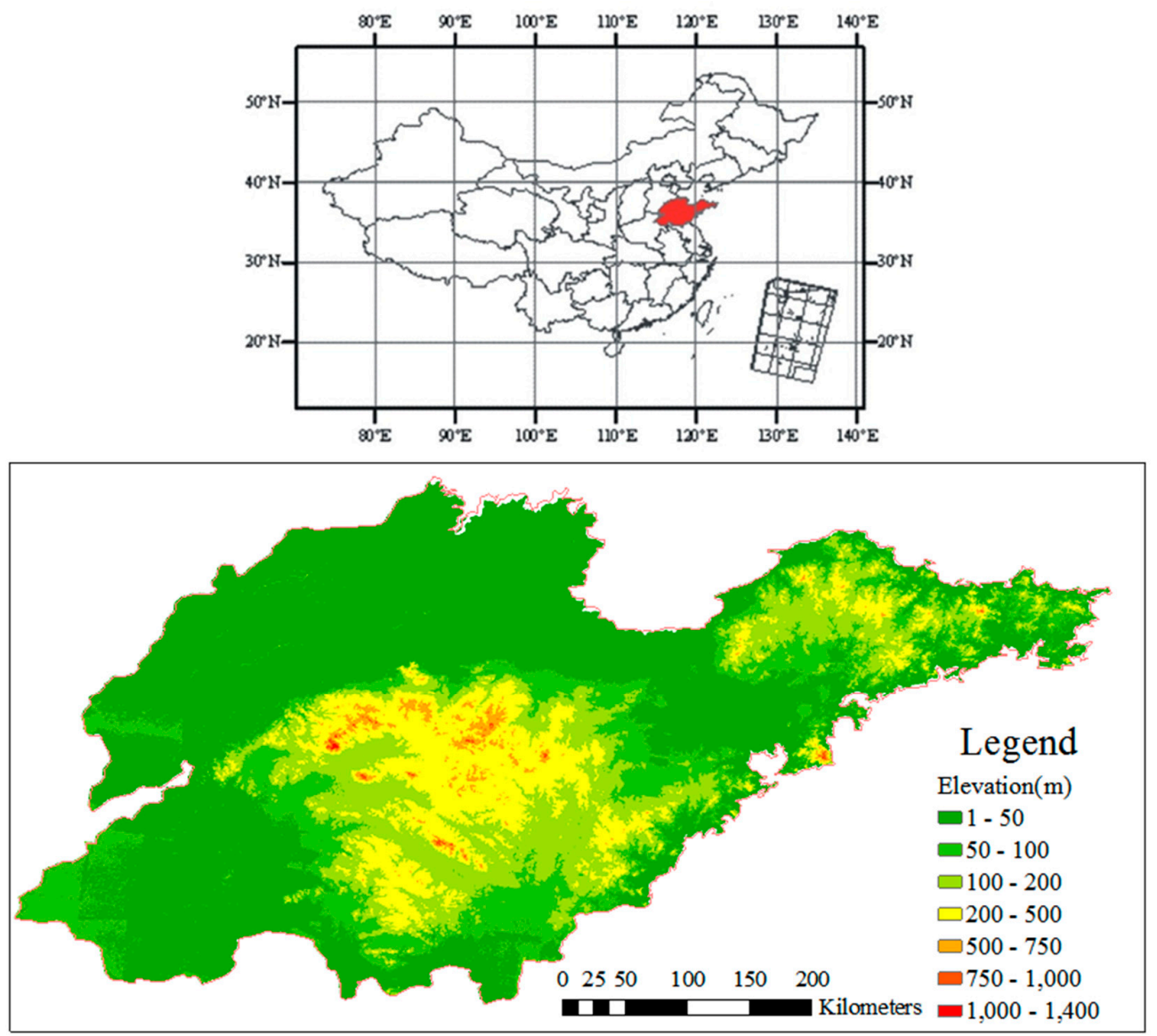

Figure 1 Location of Shandong Province

Shandong Province located in eastern coast area of China, the lower reach of the Yellow River and the middle and northern part of Beijing - Hangzhou Great Cannel. The terrain of Shandong mainly consists of plain and hilly area which occupies $55 \%$ and $28.7 \%$ of the total land area, respectively. The rising middle is Mountain and Hilly areas in the Middle and South Shandong. It takes Taiyi Mountain as its main body, gradually transits from low hills around to piedmont plain and Yellow River floodplain. In the northwest, it is Northwest Plain of Shandong, an alluvial plain formed by the Yellow River, which is one part of North Plain of China. Eastern peninsula is mostly gently fluctuated hilly areas (Fig. 1). Shandong belongs to semi-humid monsoon climate in the warm temperate zone. The climate is mild and four seasons are discernible. The mean annual temperature is 11 and northern part of Beijing - Hangzhou Great Ca50mm. Shandong Province is one of important agricultural production areas in China. Cropland distributes extensively, mainly on the Northwest Plain, Southwest Plain and Jiaolai Plain. Forest and grassland mainly distribute on the Mountain and 
Hilly areas in the Middle and South Shandong, Jiaodong Peninsula and the Yellow River Delta. Wetland distributes along the coast (Fig. 2).

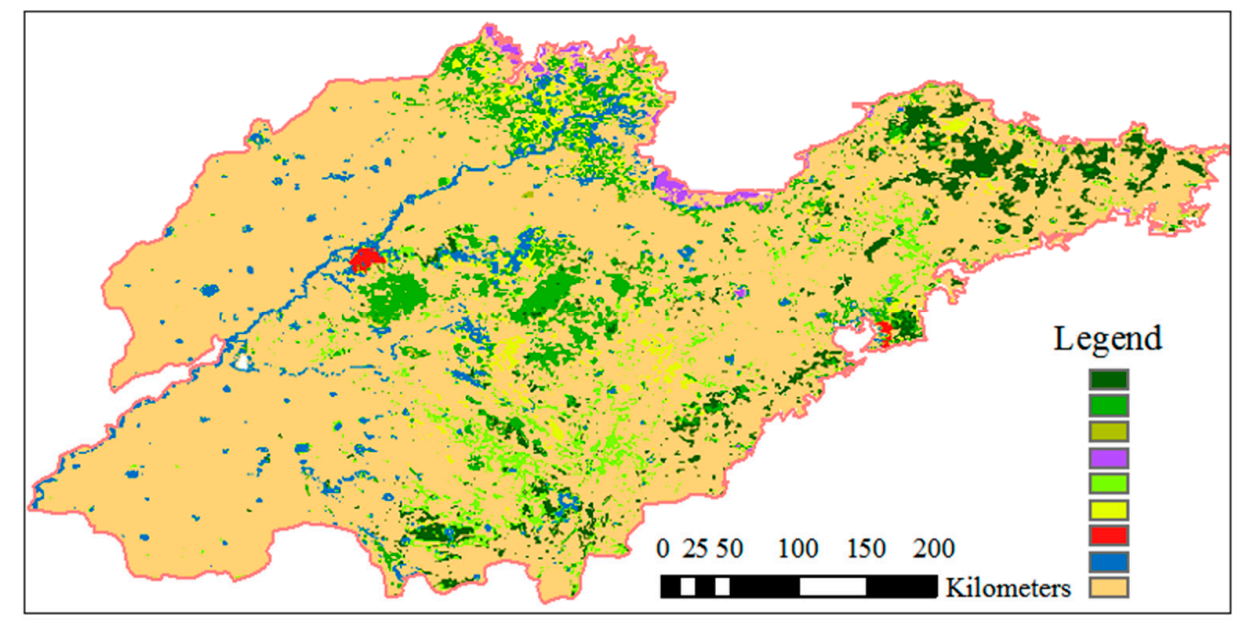

1- Evergreen coniferous forest; 2- Deciduous broadleaved forest; 3- Shrub; 4- Coastal wetland; 5-

Grassland; 6-Meadow; 7- Urban land; 8- River and lake; 9- Cropland.

Figure 2 Land use/cover in Shandong Province

\section{Data sources and methods}

\subsection{Sources of historical climate data}

Temperature data sources from the decadal mean temperature anomaly series of North China from 1380s to 1980s reconstructed on the basis of historical documents recorded in substantive local gazetteers (Wang, 1990) and integrated decadal mean temperature change series of Eastern China over the past 1000 years (Ge et al., 2012). Precipitation data sources from precipitation (drought/flood) change series of North China over the past 2000 years based on historical documents (Ge et al., 2012).

\subsection{Sources and processing of population data}

Population data sources from gazetteers of counties in Shandong Province during the Qing Dynasty (1644-1911) and the period of Republic of China (1912-1949), altogether 244 volumes which cover the 110 cities or counties in the complete research area. For one county, there are sometimes 24 versions of different times recording the amount of labors, household and population which can be validated with each other. The units of labor and household amount are Ding and Hu, respectively, which are the population tax units in China during the historical periods.

First, the ratio of labor, household amount and population is estimated. One Ding is mostly defined as an adult male aged from 16-60 who is regulated to must pay the labor tax. The ratio of numbers of labors, households, and population shows certain proportion in certain region in China over the past 300 years. Select county data recording both labor and household amount or population to calculate the ratios. It draws that 1 household has 2-3 labors and includes 5-6 persons in Shandong Province generally which is relatively reasonable at that time.

Secondly, the numbers of labors of the 17th century and 18th century, and the numbers of households of the 19th century and 20th century are indicated, for these two indexes have the most amounts of records during the corresponding times. There are 53 and 52 data for the numbers of labors in the 17th and 18th century, respectively, moreover, there are 40 and 46 data for the numbers of labors/households in the 19th century and 20th century, respectively. 26 and 44 data of population can be used in the 19th and 20th century, respectively. Therefore, it is necessary to interpolate the missed data to obtain a complete series for the 4 time sections, according to the ratios of these indexes and correlations between the 4 time sections. The interpolate results are relatively dependable, 
explained variances (R2) of model equations between the 17th and 18th century, the 18th and 19th century, the 19th and 20th century are $84.3 \%, 86.9 \%$, and $80.2 \%$, respectively (Fig. 3).

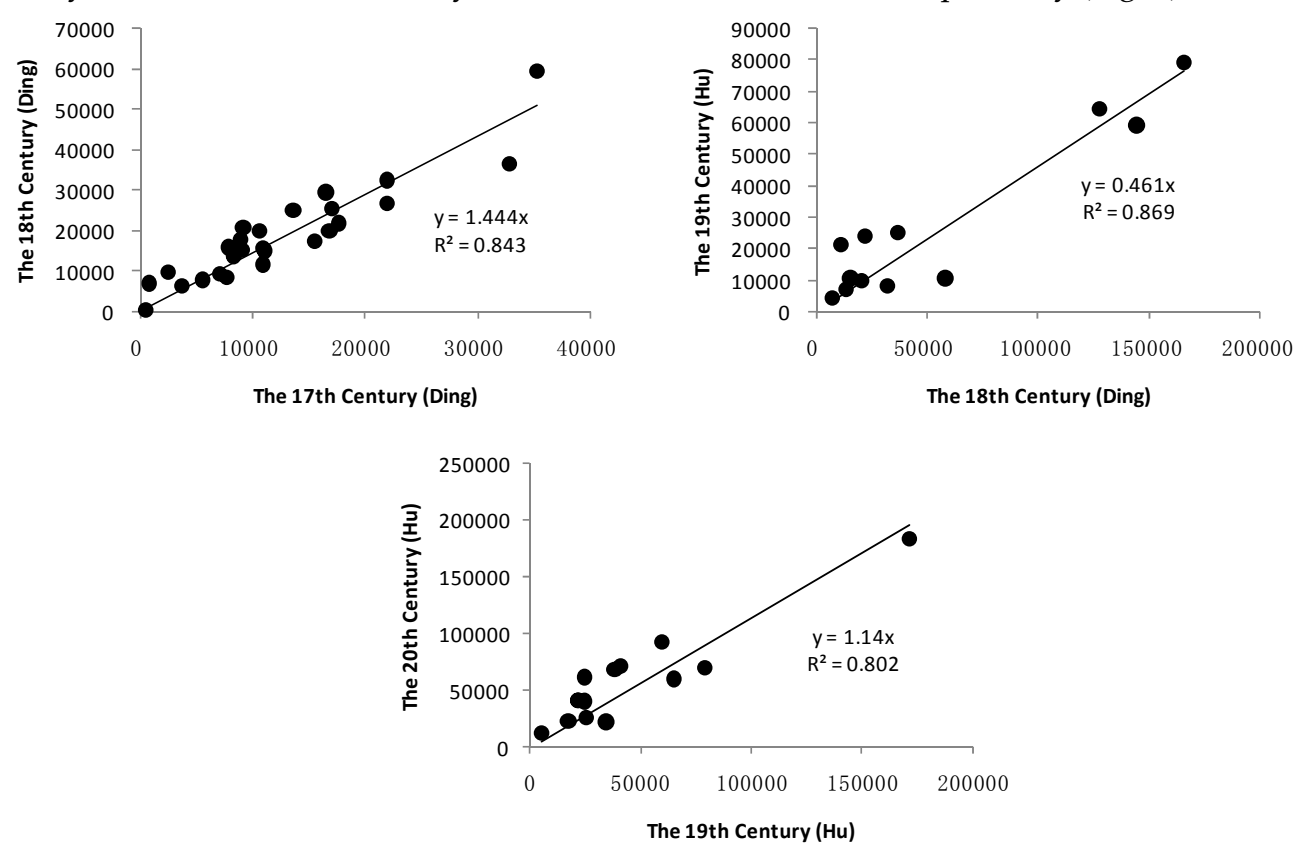

Figure 3 Correlation relationship and regression equation of labor/household amount between the different time sections

\subsection{Spatial distribution change of labor/household density and cropland areas per capita}

Divide labor or household amount at county level by county land area to obtain labor/household density in the four time-sections. Divide labor or household amount at county level in four time sections by cropland area in each county ( Yu Ye et al., 2015) to obtain cropland area per labor/household. Afterwards, according to the analysis of population data, convert the cropland area per labor/household into cropland area per capita by the equations of $1 \mathrm{Hu}=2-3 \mathrm{Ding}, 1 \mathrm{Hu}=5-6$ person. Finally, produce the spatial distribution maps of labor/household density and cropland area per capita in the four time-sections by the software of ARCGIS and analyze the spatial differences and its change. To better represent the social vulnerability in the perspective of food security, take $0.05 \mathrm{ha}$ as the basic unit of division referring to the warning line of cropland area per capita ( $0.053 \mathrm{ha})$ put forward by Food and Agriculture Organization of United Nations (FAO). The legend of cropland area per capita is expressed as the segmentations separated by the $1,2,4,8,16,32$ times of 0.05 ha, respectively.

\subsection{Spatial distribution change of pressure index on cropland}

Pressure index on cropland can measure the shortage degree of cropland resources in a certain region and reflect the pressure on cropland and the social vulnerability in the perspective of food security during the historical periods. Minimum cropland area per capita means the necessary cropland area to satisfy a person's basic food consummation at normal living level in a certain region. Since the Qing dynasty, the "warning line" of cropland area per capita in Shandong had changed, for crop yield had been improved from about 1500kg/ha to 6000kg/ha (Guo, 1995; Agriculture Department of the Shandong Province, 2014) and dietary structure based on grain remained by and large. To make historical research easier, the model put forward by Cai et al. (2002) is simplified by assuming minimum cropland area per capita in four time-sections to be 4 times as those in modern times, and minimum cropland area per capita in modern times applies the warning line of cropland area per capita $(0.053 \mathrm{ha})$ put forward by FAO. Pressure index on cropland $(\mathrm{K})$ is the ratio of minimum cropland area per capita $\left(\mathrm{S}_{\mathrm{min}}\right)$ and actual cropland area per capita $\left(\mathrm{S}_{\mathrm{a}}\right)$. Its formulation is: 


$$
\mathrm{K}=\mathrm{S}_{\min } / \mathrm{S}_{\mathrm{a}}
$$

Assume cropland area per labor and cropland area per household are $S_{d}$, $S_{h}$ respectively. According to the ratios of the numbers of labors, households and population discussed above, then, it can be obtained that:

$$
\begin{aligned}
& \mathrm{K}=\left(0.053^{*} 4^{*} 6 / 3\right) / \mathrm{S}_{\mathrm{d}}=0.424 / \mathrm{S}_{\mathrm{d}} \\
& \text { or } \mathrm{K}=\left(0.053^{*} 4^{*} 6\right) / \mathrm{S}_{\mathrm{h}}=1.272 / \mathrm{S}_{\mathrm{h}}
\end{aligned}
$$

Theoretically, when the pressure index on cropland $K<1$, cropland has no remarkable pressure; when the index $K=1$, cropland can guarantee human's normal living demand; when the index $K>1$, food production can't guarantee the normal demand and it is possible to result in food crisis. Furthermore, the degree of deviation of $\mathrm{K}$ value from 1is larger, then, the degree of security or pressure is stronger. The pressure index on cropland in each county in four time-sections is calculated. For the historical production level and efficient use of cropland is relatively lower than those in modern times after all, we divide $\mathrm{K}$ into 1-6 grades which are 0-0.4, 0.4-0.8, 0.8-1.6, 1.6-3.2, $3.2-4,>4$ respectively, considering the actual discrete distribution of $\mathrm{K}$ value. The higher index grade means the heavier pressure on sustainable cropland use and larger possibility of food crisis. We produce the spatial distribution map of $\mathrm{K}$ value by the software of ARCGIS and analyze its change. Then, for the periods with higher food risk, $\mathrm{K}$ value is interpolated by the inverse distance weighted method to identify the vulnerable center.

\subsection{Analysis of climate change and sustainable cropland use}

Compare climate change phases with the sustainable extent of cropland use in Shandong during different periods over the past 300 years. The sustainability of cropland use can be measured by above indexes including population density, cropland area per capita, pressure index on cropland. By the link of some intermediate elements such as population, agricultural production, policy adjustment and so on, the impacting process of climate change was analyzed, and society vulnerability and food sustainability during different periods were discussed.

\section{Results analysis}

\subsection{Climate change in North China over the past 300 years}

It shows that 5 regions in Eastern China including North China all existed two distinctive cold periods (1620s 1710s and 1800s 1860s) and the 20th century warm period which is the warmest period during the past 500 years. The annual average temperature in the coldest hundred years (1800 1900) was lower than that of 20 th century by $1.0^{\circ} \mathrm{C}$, and the coldest 30 years happened in 1650 1680 (Ge et al., 2012). The series of average temperature in North China since 1380 show that there existed two cold periods (1550s 1690 and 1800s 1860s) (Wang et al., 1991).

Climate in Eastern China during the Qing Dynasty (1644 1911) was humid generally, however, decadal variation is very distinctive. It appeared continuous drought in 1720, 1785, 1810 and 1877. Climate in the 20th century tended to dry in the fluctuation in which the middle of 1940s was wetter than the middle of 1960s, then, it tended to dry again since 1980s. It also shows that 3 sub-regions in Eastern China had high consistency in dry/wet change since 1680s (all humid relatively), however, dry/wet change trend of North China (dry relatively) during 1520s 1680s is converse to that of Jianghuai and Jiangnan region (wet relatively) (Ge et al., 2012).

\subsection{Spatial distribution change of Labor/household density in Shandong over the past 300 years}

From the spatial distribution map of labors/households density (Fig. 4), it can be found that there exists obvious spatial difference in labor/household density, which shows the similar pattern of cropland area in the corresponding periods. That is, it has relatively more population in the agricultural area appropriate for cultivation, while little population in the regions not appropriate for cultivation, which embodies the impact of land suitability for cultivation on population distribution. 
In the agricultural area of Northwest, Southwest Shandong and Jiaolai Plain, there distributes more population. The labor/household densities of majority cities or counties during the 17th-18th century reach above $10 \mathrm{Ding} / \mathrm{km}^{2}$, which reach above $10 \mathrm{Hu} / \mathrm{km}^{2}$ at the beginning of 20th century. In the Middle and Southern hills areas, Jiaodong Peninsula and coastal wetland regions there distributes fewer population, where labor/household densities of majority cities or counties are lower than 5 Ding $/ \mathrm{km}^{2}$ and $5 \mathrm{Hu} / \mathrm{km}^{2}$, respectively.

Population density of Shandong Province over the past 300 years has been increasing, especially in the three agricultural areas, and the spatial difference of population density from the 19th century to the beginning of 20th century was decreasing. In the Northwest, Southwest agricultural areas, the labor densities were above $10 \mathrm{Ding} / \mathrm{km}^{2}$ during the $17 \mathrm{th}-18$ th century. Till the 19 th century and the beginning of 20th century, the population densities in the whole research area were increasing, which has reached $20 \mathrm{Hu} / \mathrm{km}^{2}$ in many regions of three agricultural areas.
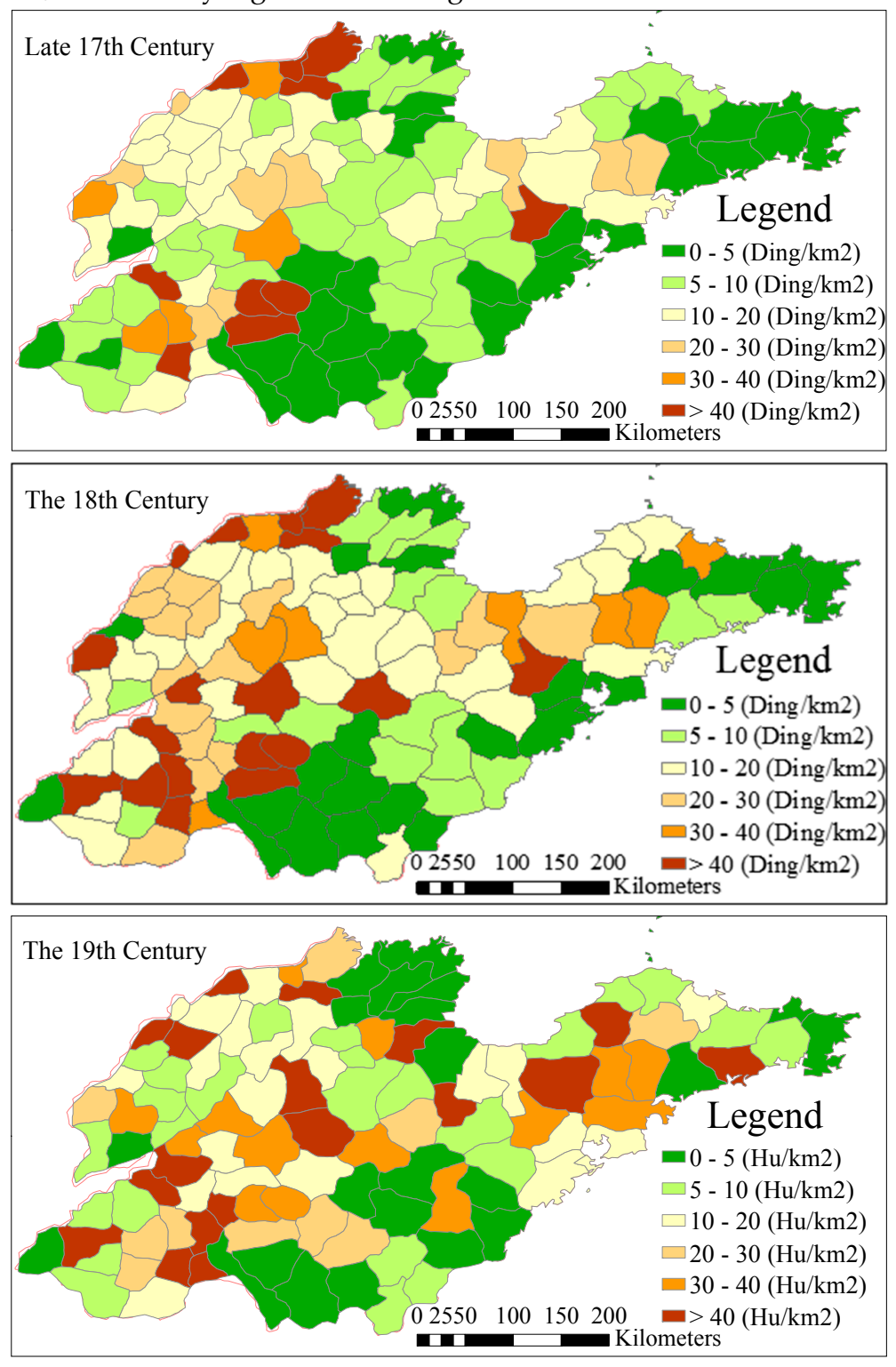


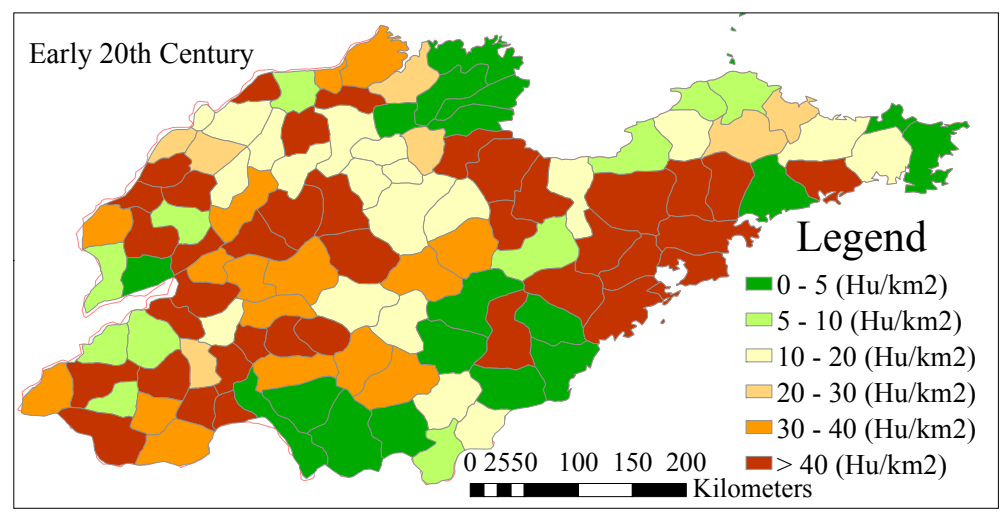

Figure 4 Spatial distribution change of labor/household density in Shandong from the late 17th century to the beginning of 20th century

\subsection{Spatial distribution change of cropland area per capita in Shandong over the past 300 years}

From the spatial distribution map of cropland area per capita in Shandong from the late 17th century to the beginning of 20th century (Fig. 5), it can be found that cropland area per capita distributes relatively uniformly and the spatial difference is less obvious than population density.

The value of cropland area per capita during the 17th - 18th century were higher, when those of majority counties were above 0.4 ha, which is 8 times higher than the modern warning line of cropland area per capita put forward by FAO. However, cropland area per capita in few counties in Binzhou, Linyi and Jining was below 4 times higher than the modern warning line, which means that food security in these regions may exist risk, with stronger social vulnerability and was most likely be affected by climatic disasters.

The value of cropland area per capita from the 19th century to the beginning of 20th century decreased generally, which represents the strength of social vulnerability and the increasing possibility of social turbulence resulted from threatened food security. During the 19th century, cropland area per capita in majority counties in the middle Shandong and Jiaodong Peninsula was below 0.1 ha, that was the 2 times higher than the modern warning line of cropland area per capita. Food security in Binzhou, Linyi, Jining, Laiwu, Tai'an, Yantai, and Weihai likely existed risk. At the beginning of 20th century, cropland area per capita in the whole research area decreased universally, especially that in majority counties in Jiaolai Plain and the middle Shandong decreased to below 0.2 ha. In Northwest and Southwest of Shandong, it appeared many counties with the cropland area per capita were lower than 0.4 ha. The numbers of vulnerable regions increased. New risk area such as Jinan, Dezhou and Qingzhou appeared at the beginning of 20th century except the food risk areas during the 19th century still existed (Fig. 5).

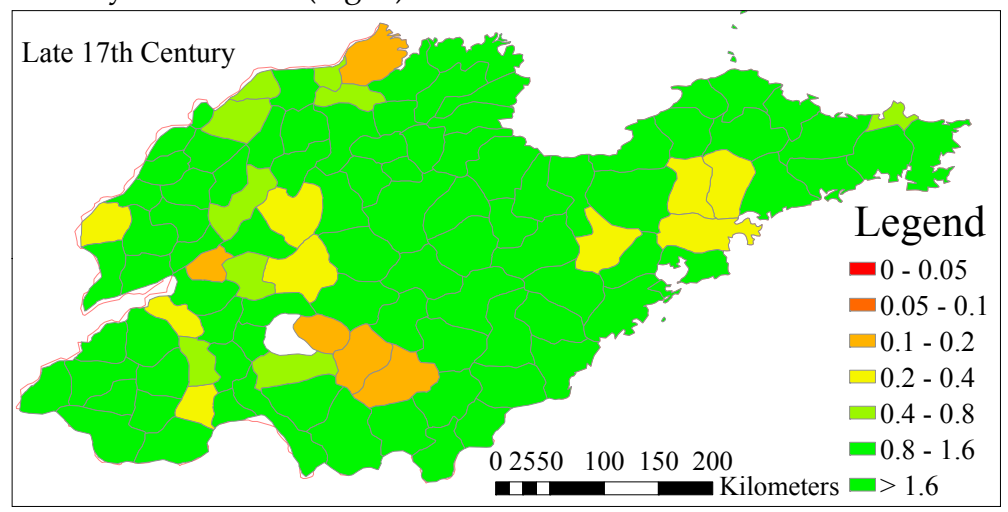



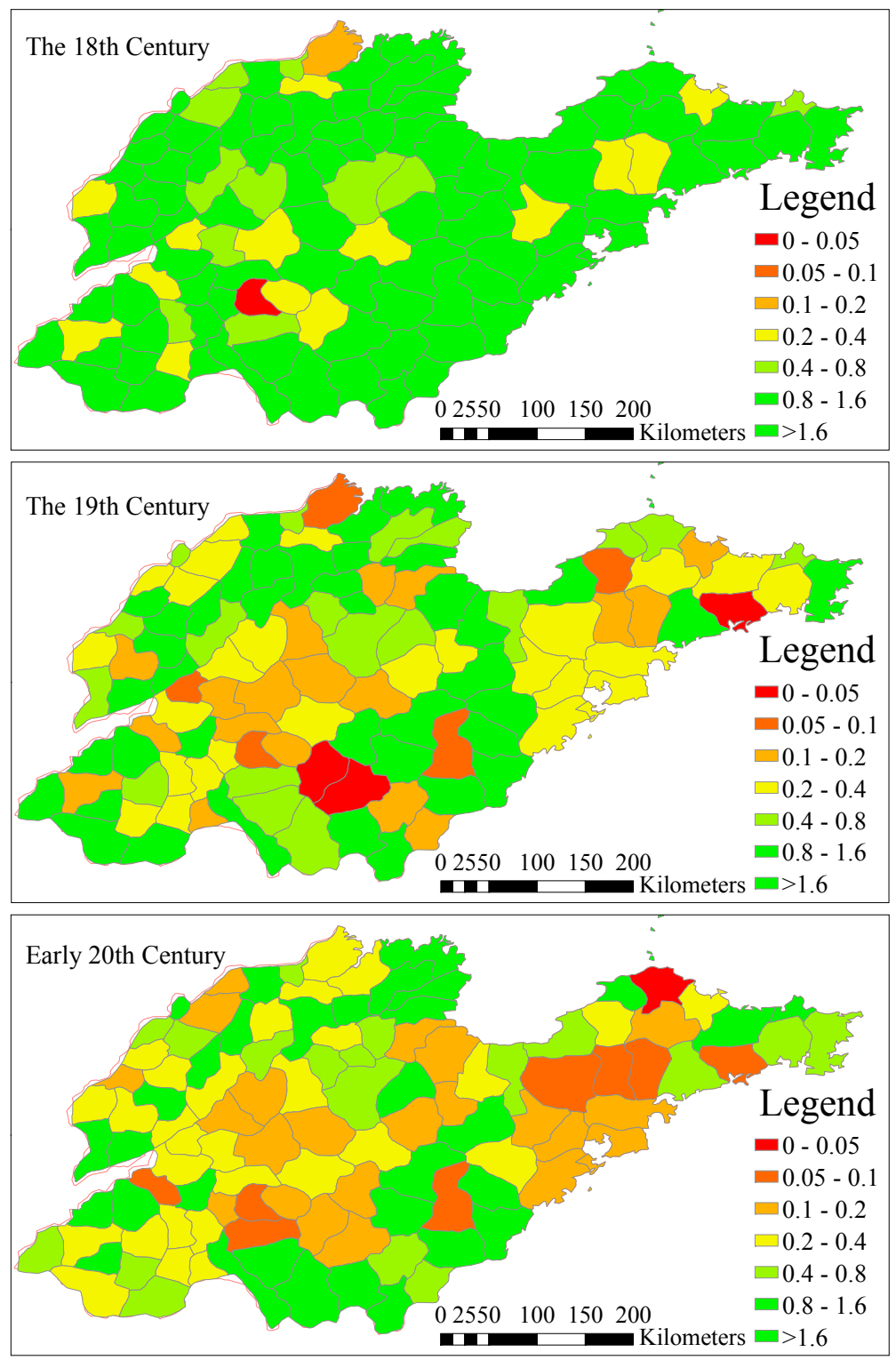

Figure 5 Spatial distribution change of cropland area per capita in Shandong from the late 17th century to the beginning of 20th century (Unit: ha)

\subsection{Spatial distribution change of pressure on cropland in Shandong over the past 300 years}

From the spatial distribution map of pressure index on cropland in Shandong from the late 17th century to the beginning of 20th century and map of its spatial pattern change (Fig. 6), it can be found that pressure index on cropland showed the similar spatial distribution as cropland area per capita and its threshold was lower than that in modern times. The pressure index on cropland distributed uniformly. It was relatively lower in the 17th - 18th century, while, overall raised during the 19th 20th century. 

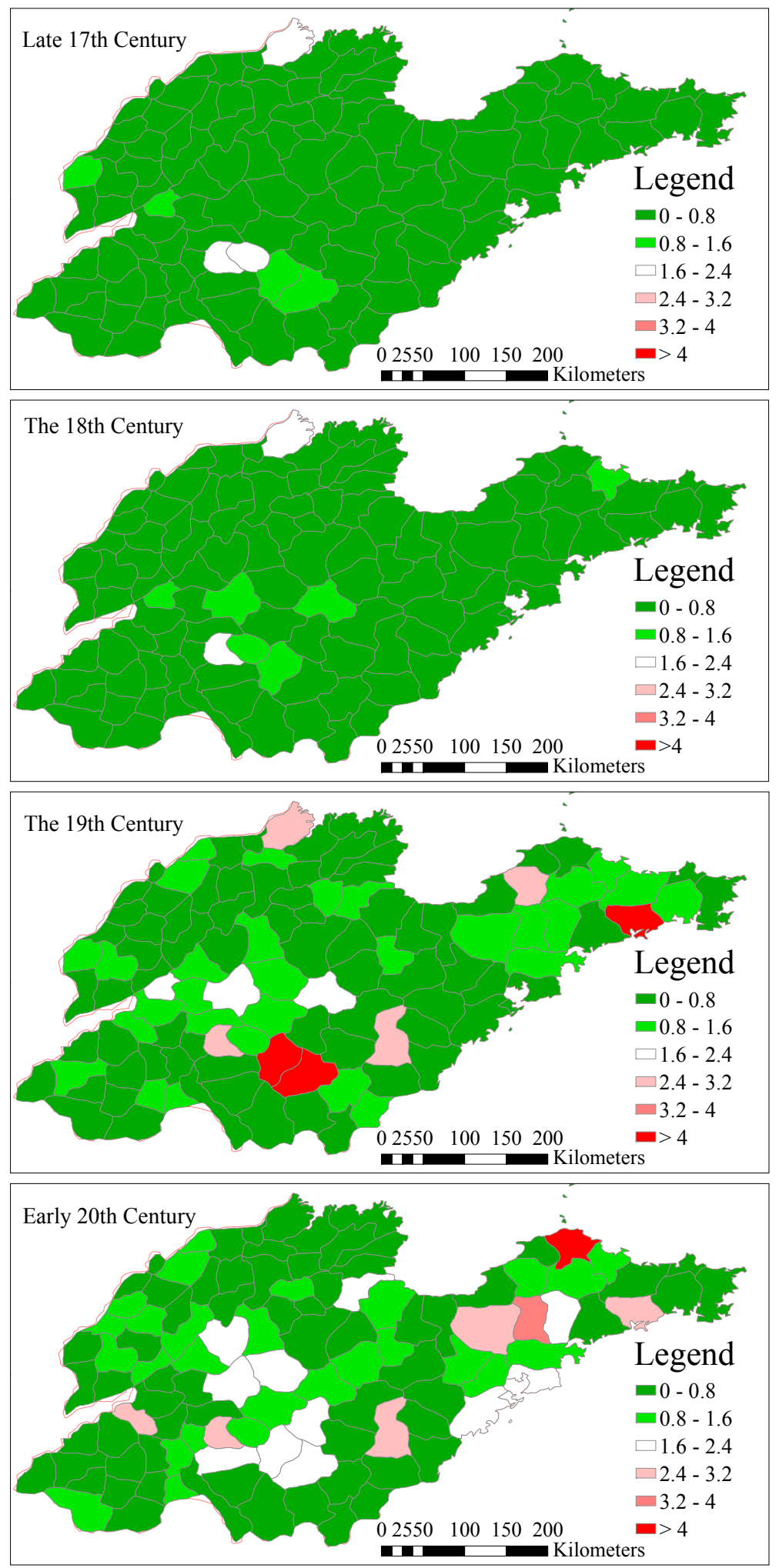

Figure 6 Spatial distribution change of pressure index on cropland in Shandong from the late 17th century to the beginning of 20th century

Pressure index on cropland in majority counties during the 17th - 18th century was below 0.8 , which means that there is no pressure on cropland, except minority regions in Jinan, Linyi and Binzhou likely exists risk of food security with the pressure index above 0.8 (Fig. 6). Till the 19th century and the beginning of 20th century, there appeared two high value centers of pressure on 
cropland in middle Shandong and Jiaodong Peninsula (Fig. 7), including some cities or counties in Linyi, Tai'an, Jinan, Laiwu, Yantai, Qingzhou, Weihai with pressure index on cropland above 1.6. With the increase of pressure on cropland, there is possibility of food crisis in these areas.
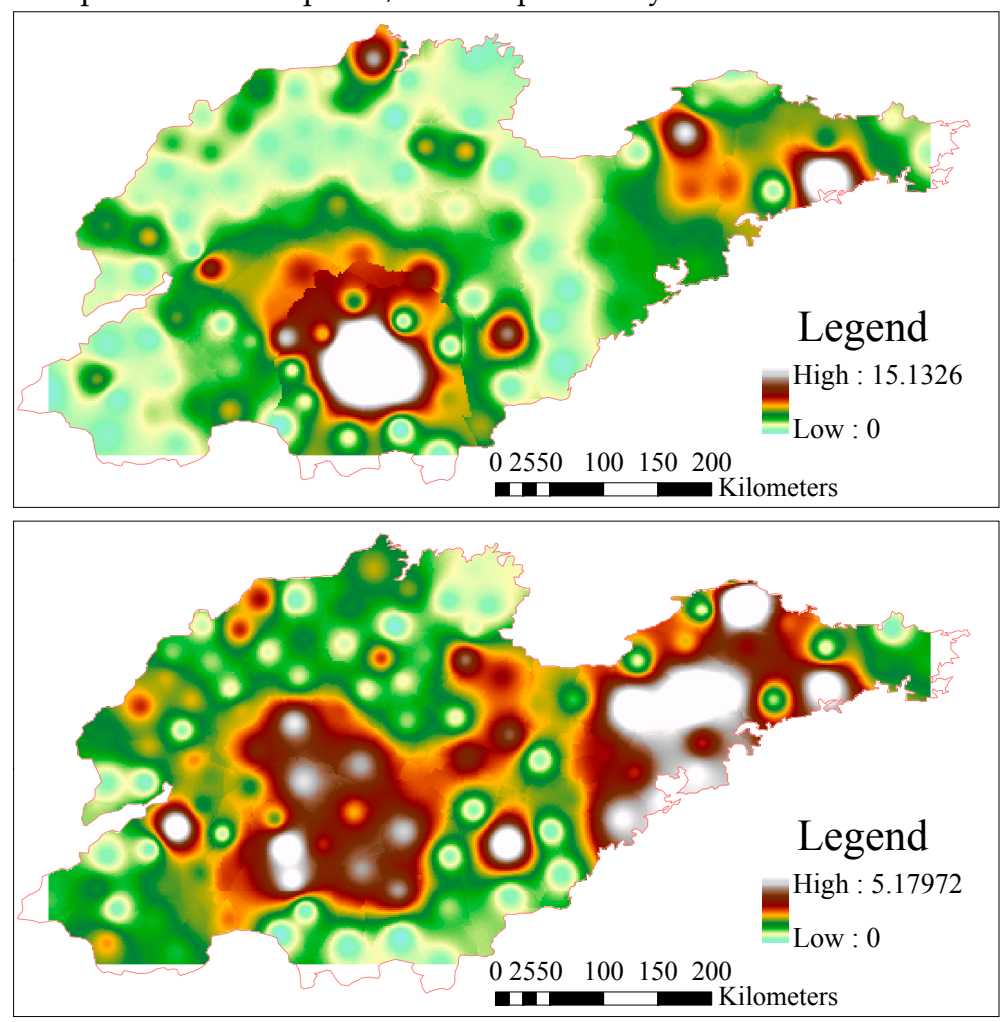

Figure 7 Spatial pattern of pressure index on cropland in Shandong during the 19th century and at the beginning of 20th century

\section{Discussion}

\subsection{Comparison between climate change phases and the sustainable extent of cropland use in Shandong}

First, it seems that higher sustainable extent of cropland use corresponds to cold period, and lower sustainable extent of cropland use corresponds to warm period in Shandong over the past 300 years. In the two cold periods (1620s 1710s, 1800s 1860s), the population density in Shandong was relatively lower when the labor/household densities of majority cities or counties during the 17th18th century were above $10 \mathrm{Ding} / \mathrm{km}^{2}$, which reached above $10 \mathrm{Hu} / \mathrm{km} 2$ at the beginning of 20th century corresponding to the 20th century warm period. Especially, the labor densities of the Northwest, Southwest agricultural areas increased from above 10 Ding $/ \mathrm{km}^{2}$ during the 17 th -18 th century to even $20 \mathrm{Hu} / \mathrm{km}^{2}$ in many regions till the beginning of 20 th century. The cropland area per capita during the 17 th -18 th century was higher above 0.4 ha, which is 8 times higher than the modern warning line of cropland area per capita put forward by FAO. From the 19th century to the beginning of 20th century, the cropland area per capita in majority counties in the middle Shandong and Jiaodong Peninsula decreased to below 0.1 ha, the 2 times higher than the modern warning line, which represents the strength of social vulnerability and the increasing possibility of social turbulence resulted from threatened food security. Similarly, pressure index on cropland in majority counties during the 17 th -18 th century was below 0.8 , which means that there is no pressure on cropland. Till the 19th century and the beginning of 20th century, there appeared two high value centers of pressure on cropland in middle Shandong and Jiaodong Peninsula where pressure index on cropland in some cities or counties reached above 1.6, meaning the possibility of food crisis in these areas. 
Second, turning point of 1680s from dry to wet relatively in North China seems to attribute to the decrease of sustainable extent of cropland use in Shandong but not very distinctive. During the 17th-18th century, the population density in Shandong was relatively lower, the cropland area per capita was higher above 0.4 ha and pressure index on cropland in majority counties was below 0.8 , which means that there is no pressure on cropland during the period before and after 1680s. It is likely that the effect of dry/wet change on sustainability of cropland use is not obvious as that of temperature change.

\subsection{Impacting process of climate change and sustainability of cropland use}

Many researchers have analyzed the relationships between climate change or extreme climatic events with refugees and social stability in North China (Ye, et al., 2004; Xiao, 2011; Fang et al., 2007; Ye and Fang, 2013; Xiao et al., 2013). These case studies all showed that the impact of historical climate change on social stability in this area often took an effect by the failure of food production. In this research, the intermediate elements of population, cropland area per capita and pressure on sustainable cropland use were considered to better understand the impacting and response process of climate change.

It appeared that warm climate is beneficial to population increase and agricultural development, which brought in the pressure on sustainability of cropland use finally. In the cold periods, the population density in Shandong was relatively lower and the cropland area per capita was higher. There is no pressure on sustainable cropland use. In the 20th century warm periods, population density in Shandong increased faster than cropland area which led to the decrease of cropland area per capita, then the lowered sustainability of cropland use. It would intensify the social conflict and increase the probability of social revolts. So, the impacting process of climate change can be sketched as Climate change-Population and Cropland area-Cropland area per capita-Food sustainability and society vulnerability-Social stability.

\subsection{Special view of this research and its scientific value}

Although, there probably still exists some deviation in the reconstructed results of population and cropland area per capita mainly resulted from population calculation and data interpolation, this paper provides a perspective of food security and social vulnerability in the research area of impact of historical climate change and related risk. To certain extent, it makes up for the deficiency of paying more attention to the comparison of series of climate change and social results while ignore some intermediate links in the impact process and social vulnerability in this research area nowadays. It looks forward to evaluating human society's ultimate affected degree by historical climate change or risk with more accuracy by combining social vulnerability and human adaptation actions with climatic related hazards and physical exposure. It also gives reference to modern sustainable cropland use.

\section{Conclusions}

By the method of historical documents, regression analysis, model of pressure index on cropland and GIS, this paper reconstructed spatial pattern of labor/household density, cropland area per capita and pressure index on cropland at county level in Shandong Province during the 17th-20th century. Then it analyzed the impacting process of climate change and sustainability of cropland use during the different periods. It drew conclusions as follows:

(i) Spatial difference of labor/household density was distinctively, which shows the effect of land suitability for reclamation on the distribution of population. In agricultural area such as Northwest and Southwest Shandong and the Jiaolai Plain, density of labor/household in majority of cities/counties reached above $10 \mathrm{Ding} / \mathrm{km}^{2}$ during the 17th-18th century. At the beginning of 20th century most of cities/counties reached above $10 \mathrm{Hu} / \mathrm{km}^{2}$. While, in hill areas of the middle and south Shandong, the Jiaodong Peninsula and coastal swamp area it distributed fewer population. The 
density of labor/household in many cities/counties in these regions was below 5 Ding/ $/ \mathrm{km}^{2}$ or $5 \mathrm{Hu} /$ $\mathrm{km}^{2}$ from the 17 th century to the beginning of the 20th century.

(ii) The spatial distribution of cropland area per capita in Shandong over the past 300 years was relatively uniform, which shows the effect of the uniform tax system on cropland area per capita. During the 17th-18th century, cropland area per capita was higher, which was above 0.4 ha in majority of regions. From the 19th century to the beginning of the 20th century cropland area per capita decreased extensively. Social vulnerability became strengthen and the possibility of social turbulence resulted by food security increased. Especially in the JiaolaiPlian and the middle Shandong, cropland area per capita in majority of cities/counties was below 0.1ha. Food security in Binzhou, Linyi, Jining, Laiwu, Taian, Yantai, Weihai, Jinan, Dezhou, Qingzhou most likely existed risk.

(iii) The pressure index on cropland also shows the similar spatial distribution as cropland area per capita, but its threshold is lower than that in modern times. The pressure index on cropland in the majority of regions was lower than 0.8 during the 17th-18th century and there was no pressure on cropland. During the 19th century and the beginning of the 20th century, it appeared two high value center of pressure on cropland in Middle Shandong and the Jiaodong Peninsula. The pressure index on cropland in many cities/counties in the regions of Linyi, Taian, Jinan, Laiwu, Yantai, Qingzhou, Weihai was higher than 1.6. The pressure on sustainable cropland use increased remarkably and there existed probability of food crisis.

(iv) Warm climate is beneficial to population increase and agricultural development, which brought in more and more pressure on sustainability of cropland use finally. It would intensify the social conflict and increase the probability of social revolts. The impacting process of climate change was sketched as Climate change-Population and Cropland area-Cropland area per capita-Food sustainability and society vulnerability-Social stability. The transformation from dry to wet relatively in 1680s in North China seems to attribute to the decrease of sustainable extent of cropland use in Shandong but not very distinctive.

Acknowledgments: This work was supported by the National Natural Science Foundation of China (Grant No. 41471156) and Strategic Priority Research Program from Chinese Academy of Sciences (XDA05080102).

\section{References:}

1. Agriculture Department of the Shandong Province. 2014. Agriculture information website of Shandong province (www.sdny.gov.cn).

2. Bian, L. 1995. Folk measure method and essence of farmland area in South China during Ming dynasty and Qing dynasty. China Agricultural History 14(2): 49-56.

3. Cai, Y. L., Z. Q. Fu, E. F. Dai. 2002. The minimum area per capita of cultivated land and its implication for the optimization of land resource allocation. Acta Geographica Sinica 57(2): 127-134.

4. Fang, X. Q., Y. Ye, Z. Z. Zeng. 2007. Extreme climate events, migration for cultivation and policies: A case study in the early Qing Dynasty of China. Science in China (Series D: Earth Sciences) 50(3): 411-421.

5. Fang, X. Q., J. Y. Zheng and Q. S. Ge. 2014. Historical climate change impact-response processes under the framework of food security in China. Scientia Geographica Sinica 34(11): 1291-1298.

6. Field, C. B., V. R. Barros, M. D. Mastrandrea, et al. 2014. Climate Change 2014: Impacts, Adaptation and Vulnerability, Contribution of Working Group II to the Fifth Assessment Report of the International Panel on Climate change(www. Ipcc.cn).

7. Ge, J. X. 2002. The history of China's population. Shanghai: Fudan University Press.

8. Ge, Q. S., J. H. Dai, F. N. He, et al. 2003. Change of the amount of cropland resource and analysis of driving forces in partial provinces in China during the past 300 years. Progress in Natural Science 13(8): 825-832.

9. Geng, Z. J. 2000. Tentative analysis of question of men's and farmland's discount in Shanxi during Qing dynasty. China Agricultural History 19(1): 67-71.

10. Guo, S. Y. 1995. Food production in rainfed agricultural region in North China in the Qing Dynasty. Research on Chinese economic history, (1): 22-44.

11. Haug, G. H., D. Gunther, L. C. Peterson, et al. 2003. Climate and the collapse of Maya civilization. Science 299(5613):1731-1735.

12. He, B. D. 1988. Verification and evaluation of ancient and today's land data in China. 
13. He, F. N., S. C. Li, X. Z. Zhang. 2011. The reconstruction of cropland area and its spatial distribution pattern in the mid-northern Song Dynasty. Acta Geographica Sinica 66(11): 1531-1539.

14. Hsu, K. J. 1998. Sun, climate, hunger and mass migration. Science in China (Ser. D) 41(5):449-472.

15. James, J., McCarthy, F. Osvaldo, et al. 2001. Climate Change 2001:Impacts, Adaptation and Vulnerability, Contribution Of Working Group II to the Third Assessment Report of the Intergovernmental Panel on Climate change. UK: Cambridge University Press.

16. Li, B. Z. 1999. Climate change and several times of Chinese historical population fluctuation. Population Research 23(1): 15-19.

17. Liu, X. T., Y. L. Cai. 2010. Grain security of basic cropland pressure index in Shandong Province. Population, Resources and Environment 20(s1): 334-337.

18. Niu, P. H. 1990. Table of administrative division evolution during the Qing Dynasty. China Cartographic Publishing House, Beijing.

19. Ren, G. Z., X. G. Zhao, S. J. Chao, et al. 2008. Temporal-spatial analysis of cultivated land pressure in China based on the ecological tension indexes of cultivated land. Journal of Arid Land Resources and Environment 22(10): 37-41.

20. Richard, S. J., T. S. Wagner. 2010.Climate change and violent conflict in Europe over the last millennium. Climatic Change 99: 65-79.

21. Shi, Z. X. 2000. Analysis on change of population and land in the area of Gan, Ning and Qing during the late Qing dynasty. China Agricultural History 19(1): 72-79.

22. Tian, Y. C., J. Li, Z. Y. Ren. 2012. Analysis of cropland change and spatial-temporal pattern inLoess Plateau over the recent 300 years. Journal of Arid Land Resources and Environment 26(2): 94-101.

23. Wan, H. 2000. Historical comparison between cropland numbers in China during Ming dynasty and early Qing dynasty. China Agricultural History 19(4): 34-40.

24. Wang, S. W., Wang R. S. 1991. Reconstruction of temperature series of North China from 1380s to 1980s. Science in China: Series B 34(6): 751-759.

25. Xiao, L. B., X. Q. Fang, Y. Ye. 2013. Reclamation and revolt: social responses in Eastern Inner Mongolia to flood/drought-induced refugees from the North China Plain 1644-1911. Journal of Arid Environments 88(1): 9-16.

26. Xiao, L. B., Y. Ye, B. Y. Wei. 2011. Revolts frequency during 1644-1911 in North China Plain and its relationship with climate. Advances in Climate Research 2(4): 218-224.

27. Xie, Y. W., Wang XQ, Wang GS, et al. 2013. Cultivated land distribution simulation based on grid in middle reaches of Heihe River Basin in the historical periods. Advances in Earth Science 28(1): 71-78.

28. Ye, Y., X. Q. Fang. 2012. Expansion of cropland area and formation of the eastern farming-pastoral ecotone in northern China during the twentieth century. Regional Environment Change 12(4): 923-934.

29. Ye, Y., X. Q. Fang, Q. S. Ge, et al. 2004. Response and adaptation to climate change indicated by the relationship between revolt and drought-flood in Shandong Province during middle and late Qing Dynasty. Scientia Geographica Sinica 24(6): 680-686.

30. Ye, Y., X. Q. Fang, M. Khan. 2012.Migration and reclamation in Northeast China in response to climatic disasters in North China during the past 300 years. Regional Environmental Change 12(1): 193-206.

31. Ye, Y., X. Q. Fang, Y. Y. Ren, et al. 2009.Cropland cover change in Northeast China during the past 300 years. Science in China (Series D: Earth Science) 52(8): 1172-1182.

32. Zhang, D. E., H. C. Li, T. L. Ku, et al. 2010. On linking climate to Chinese dynastic change: Spatial and temporal variations of monsoonal rain. Chinese Science Bulletin 55(1): 77-83.

33. Zhou, R. 2001. Integrated review and new calculation of cropland area during the early Qing dynasty. Jianghan Tribune 9: 57-61.

34. Ye, Y., X. Q. Wei, F. Li, et al. 2015. Reconstruction of cropland cover changes in Shandong Province over the past 300 years. Scientific Reports (submitted).

35. Ge Q. S., Zheng J. Y., Hao Z. X., et al. 2012. General characteristics of climate changes during the past 2000 years in China. Sci China Earth Sci 42(6): 934-942. 